\title{
In vitro study on the immunomodulatory effects of differently functionalized silver nanoparticles on human peripheral blood mononuclear cells
}

\author{
Barbara Vuković ${ }^{1,2} \cdot$ Željko Cvetić $^{3} \cdot$ Krešo Bendelja $^{3} \cdot$ Rinea Barbir $^{4} \cdot$ Marija Milić $^{1,2} \cdot$ Blaženka Dobrošević ${ }^{1}$. \\ Vatroslav Šerić $^{1,2} \cdot$ Ivana Vinković Vrček ${ }^{4}$
}

Received: 6 April 2021 / Accepted: 28 August 2021 / Published online: 2 September 2021

(c) Society for Biological Inorganic Chemistry (SBIC) 2021

\begin{abstract}
The interaction of silver nanoparticles (AgNPs) with the immune system has not yet been sufficiently elucidated even though they belong to the most investigated and exploited group of nanomaterials. This study aimed to evaluate immunomodulatory effect of four different AgNPs on human peripheral blood mononuclear cells (hPBMCs). Fresh hPBMCs were exposed to the small sized $(\sim 10 \mathrm{~nm})$ AgNPs immediately after isolation from the whole blood of healthy volunteers. The study considered coating-, time- and dose-dependent response of hPBMSc and stimulation of both early and intermediate activation of lymphocytes and monocytes using flow cytometry. The AgNPs differed in surface charge and were stabilised with polyvinyl pyrrolidone (PVP), poly-L-lysine (PLL), bis(2-ethylhexyl) sulfosuccinate sodium (AOT) or blood serum albumin (BSA). Response of hPBMCs to coating agents and ionic Ag form was evaluated to distinguish their effect from the AgNPs action as they may be released from the nanosurface. There was no significant effect of any tested AgNPs on relative count of hPBMCs subpopulations. The T-cells and monocytes were not activated after treatment with AgNPs, but the highest concentration of PLL- and BSA-AgNPs decreased density of CD4 and CD8 markers on T-helper and T-cytotoxic cells, respectively. The same AgNPs activated B- and NK-cells. Ionic Ag activated T-, B- and NK-cells, but at very higher concentration, whereas only PLL exhibited immunomodulatory activity. This study evidenced immunomodulatory activity of AgNPs that may be fine-tuned by the design of their surface functionalization.
\end{abstract}

Ivana Vinković Vrček

ivinkovic@imi.hr

1 Department of Clinical Laboratory Diagnostics, University Hospital Centre Osijek, Josipa Huttlera 4, 31000 Osijek, Croatia

2 Faculty of Medicine, Josip Juraj Strossmayer University of Osijek, Josipa Huttlera 4, 31000 Osijek, Croatia

3 Center for Research and Knowledge Transfer in Biotechnology, University of Zagreb, Rockefellerova 10, Zagreb, Croatia

4 Institute for Medical Research and Occupational Health, Ksaverska cesta 2, 10000 Zagreb, Croatia 


\section{Graphic abstract}

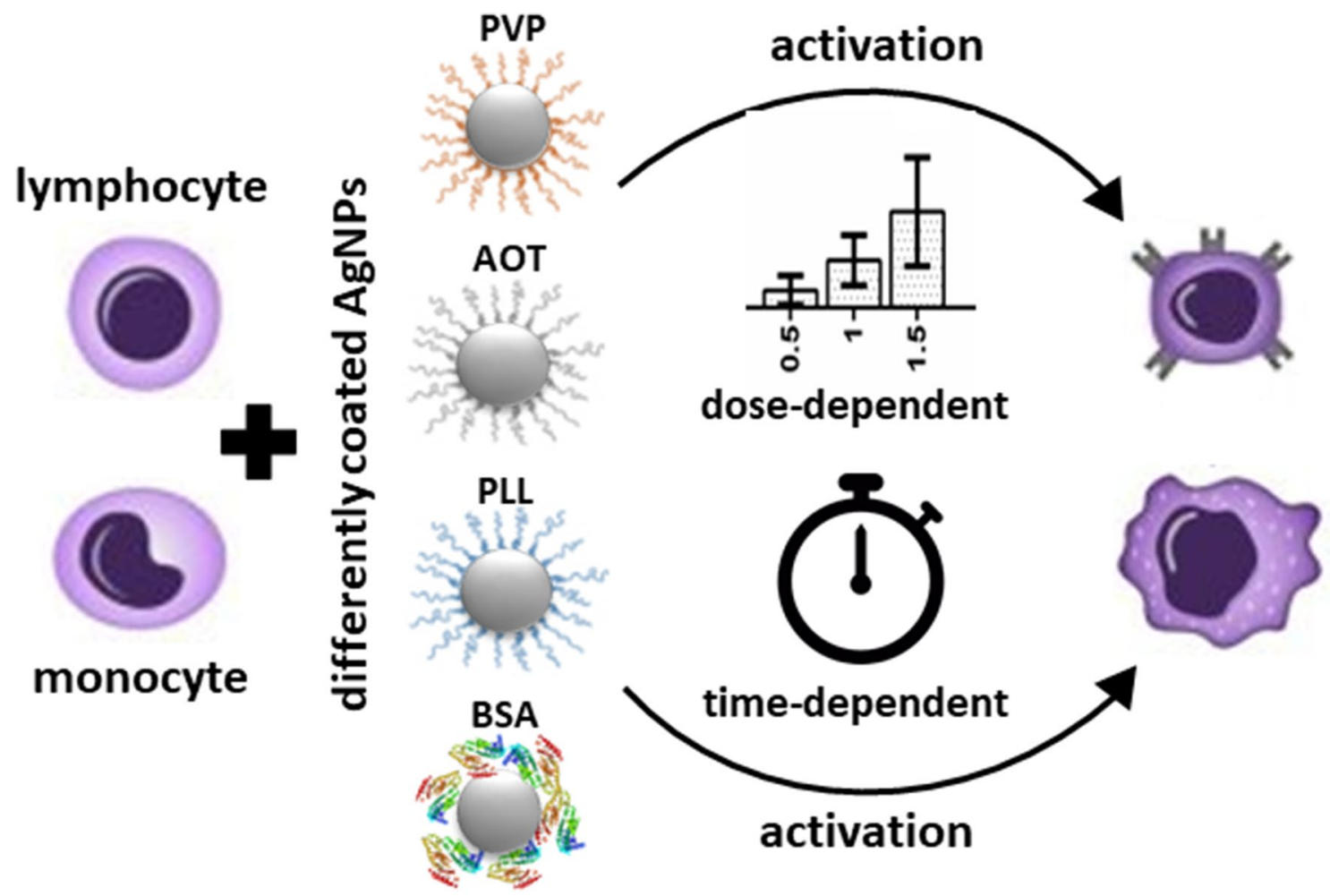

Keywords Particle surface functionalization · Human peripheral blood mononuclear cells · Flow cytometry · Activation · Surface cell markers

\section{Introduction}

The engineering of silver-based nanomaterials (NMs) has experienced a tremendous technological evolution in the last decade. Although antibacterial activity of silver has been well known since the development of medicine in ancient civilizations, its inclusion in nanostructures has allowed increased biocompatibility and development of more efficient nanoproducts for biomedicine [1]. Thus, silver nanoparticles (AgNPs) became one of the most investigated and exploited NMs due to their unique optical, electrical and biological properties [2]. Among numerous biomedical applications such as coatings for medical device and tissue regeneration materials, AgNPs awoke tremendous interest in therapeutic applications including drug or vaccine delivery platforms. Emerging problem of drug resistance emphasized broad variety of AgNPs designs as promising alternatives $[1,3]$. However, interaction of AgNPs with the immune system remains a key enigma for their implementation in such therapeutic tools.

Like many other NMs, AgNPs may easily enter the human body through many different routes (respiratory, gastrointestinal, dermal) breaching through natural barriers and entering the bloodstream. Circulating blood cells represent the first line of AgNPs interaction with human immune system that either eliminate or tolerate xenobiotics. Immune blood cells belong to innate and adaptive immunological systems. Innate immunity, represented by polymorphonuclear leukocytes (neutrophils, basophils, eosinophils) and mononuclear cells (monocyte/macrophages, dendritic cells, natural killer (NK) cells), is nonspecific, immediate action and the first line of defense without creating a long-lasting memory. Adaptive immune system, represented by T- and B-lymphocytes, evolves over time and develops immunological memory to specific foreign antigens from primary encounter [2,3]. Metallic NPs can be designed to interact with antigen presenting cells in bloodstream causing adaptive immunity (T- or B-cell) activation as already manifested for adjuvant effects of AgNPs in mice [4]. Modulating innate immunity, engineered AgNPs can suppress neutrophil cell activation and prevent inflammation or enhance immune response through neutrophil extracellular traps release [1-5].

In general, nanomaterials, as foreign substances, can be eliminated or tolerated by immune system. When designed 
for biomedical purposes, it is crucial to first determine what kind of immune reaction AgNPs are supposed to achieve [1, 3]. There are several possible outcomes of AgNPs interaction with immune cells: immunotoxicity, immunocompatibility or immunomodulation. Immunotoxicity is always undesirable consequence resulting in excessive activation of immune response or damage of immune system that finally cause diverse pathological manifestations in organism. Immunocompatibility implies AgNPs application that avoids immune system that is desirable for antimicrobial AgNPsbased products as well as for nanovectors for drugs or gene delivery. Immunomodulation can occur as stimulation or suppression of immune system. Silver-based nanovaccines act as antigens or adjuvants and stimulate immunization. AgNPs used as anti-inflammatory drugs are supposed to suppress immune response in antitumor therapy or therapy of inflammatory and autoimmune diseases [3, 5]. Depending on the type of AgNPs interaction with immune system, AgNPs-based medical products may be designed in any of these directions.

Antiviral activity of AgNPs has been already reported against various viruses such as rhinovirus, respiratory syncytial virus, human immunodeficiency virus type 1 (HIV-1), herpes simplex virus type 1 (HSV-1) or hepatitis B virus [1, 5-9]. Studies on AgNPs interaction with HIV-1 revealed that therapeutic ability of AgNPs is achieved through binding on glycoprotein 120 of CD4 receptor on the surface of T-helper cells, which represents the binding spot for this virus [9]. Inhibition of HIV binding on T-helper cell receptors by specifically functionalized AgNPs showed as a promising strategy to prevent immunodeficiency caused by this ever-challenging virus $[2,9]$. The AgNPs inhibitory effect depends on their design; the strength of the inhibition could be changed by manipulating the size and surface functionalization. Thus, development of AgNPs-enabled therapeutic agents against SARS-CoV-2 and other ever-mutating viruses should not be disregarded strategy in managing the global health problem with COVID-19 pandemic.

Immunomodulatory action of AgNPs is important also for targeted anticancer therapy of both solid and liquid tumors as therapeutic efficacy is based on combination of AgNPs cytotoxic, antiangiogenic, and immunomodulatory potential $[10,11]$. AgNPs can be used as immunosuppressants per se or as nano-carriers for anti-inflammatory drugs or DNA-vaccines altering the immune microenvironment of tumor. Recent study showed that plasmid DNA complexed with PLL-coated polystyrene NPs induce an elevation of cytotoxic CD8 + T-lymphocytes, which inhibited tumor growth in EG7 tumor cell line [12]. Chakraborty et al. reported anticancer activity of AgNPs coated with mice serum albumin (MSA) that successfully inhibited murine fibrosarcoma cells by oxidative stress-induced immunomodulation [13]. Unlike localized solid tumors, liquid tumors are usually spread all over the bloodstream, making selective targeting and treatment much more difficult. The other problem of targeting leukemic cells in blood is activation of innate immunity and possibility of eliminating AgNPs by phagocytic cells or opsonization by blood proteins. In addition, cytotoxic and immunomodulatory effects of AgNPs have been already recognized as promising tools in acute myeloid leukemia treatment, but future design of antileukemic AgNPs must reach significantly higher efficacy and specificity [14-16].

Our previous work showed how different surface functionalization affects toxicity of AgNPs in human peripheral blood mononuclear cells (hPBMCs), prominent representatives of circulating immune cells [17]. Results showed increased internalization of AgNPs in hPBMCs in a doseand time-dependent manner leading to excessive production of reactive oxygen species and depletion of mitochondrial membrane potential and finally to apoptosis and cell death. Among AgNPs stabilized with neutral polyvinyl pyrrolidone (PVP), positively charged poly-L-lysine (PLL), negatively charged bis(2-ethylhexyl) sulfosuccinate sodium (AOT) and blood serum albumin (BSA) as protein coating, the highest cytotoxic potential in hPBMCs was observed for PLL- and BSA-coated AgNPs. Minimally toxic conditions (survival of $>90 \%$ cells) were also determined for all four types of AgNPs [17].

Here, we aimed to evaluate immunomodulatory effect of these four different AgNPs by exposing hPBMCs cells to low, non-toxic doses of AgNPs. The hPBMC were isolated from fresh venous blood and changes in their functionality upon exposure to different AgNPs was evaluated by flow cytometry method (FCM). Such approach enabled easier and faster evaluation of hPBMCs functionality by FCMbased determination of surface antigens expression compared to semiquantitative, time- and labor-intensive proliferation assay [18]. Immunomodulatory effect of AgNPs on hPBMC was evaluated considering coating-, time- and dose-dependent manner and investigating stimulation of both early and intermediate activation of lymphocytes and monocytes. Considering that hPBMCs express many different surface receptors involved in various specialized cell functions, we also investigated how AgNPs affect them. Simultaneous experiments with $\mathrm{Ag}^{+}$and coatings used for AgNPs functionalization were conducted to distinguish the immunomodulatory action of AgNPs from the effects of $\mathrm{Ag}$ ions or from the coating agents per se. Search performed in scientific databases Web of Science and PubMed on 2nd March 2021 revealed no study that reports comprehensive and systematic evaluation of immunomodulatory effects of AgNPs as designed by us and reported here. Results on AgNPs immunomodulatory effect on B-cells, T-cells, T-helper cells, T-cytotoxic cells, NK-cells and monocytes obtained by FCM approach provide important science-based 
evidence for design of more efficient and safer AgNPs-based therapeutic products.

\section{Materials and methods}

\section{Synthesis and characterization of AgNPs}

Detailed description on preparation of PVP-, PLL-, AOTand BSA-coated AgNPs is given in our previous paper [17, 18, 20]. Briefly, AgNPs were synthesized with sodium borohydride in presence of four different surface coatings (PVP, PLL, AOT and BSA). Each freshly prepared AgNPs was characterized in ultrapure water (UPW) at the concentration of $10 \mathrm{mg} \mathrm{Ag} / \mathrm{L}$ by means of primary size, size distribution, $\zeta$ potential and release of $\mathrm{Ag}^{+}$ions. The size distribution by volume and $\zeta$ potentials were measured by dynamic (DLS) and electrophoretic light scattering (ELS) methods, respectively, on a Zetasizer Nano ZS instrument (Malvern Instruments, Worcestershire, UK). Visualization of AgNPs was performed by transmission electron microscopy (TEM) on an instrument Zeiss 902A (Oberkochen, Germany) operated in bright field mode at an acceleration voltage of $80 \mathrm{kV}$. Images were taken using a Canon PowerShot S50 camera (Canon, Tokyo, Japan). Samples were prepared using a Formvar®-coated copper grid (Agar Scientific, Stansted, UK). Primary size was determined from the cross-sectional area of the AgNPs by inspecting at least 100 particles per AgNPs type. Release of $\mathrm{Ag}^{+}$ions fraction from the AgNPs surface was determined by ultrafiltration of AgNPs suspension using Amicon-4 Ultra centrifugal filter units with a cutoff size of $3 \mathrm{kDa}$ (Merck Millipore, Darmstadt, Germany) at the $15000 \times g$ for $30 \mathrm{~min}$. Released $\mathrm{Ag}$ fraction was analyzed in filtrates by the graphite furnace atomic absorption spectrometer (GFAAS) (Perkin Elmer AAnalyst 600, Perkin Elmer, Shelton, USA).

\section{Preparation of hPBMCs cells}

Whole blood samples were collected in vacutainers with heparin-anticoagulant from three healthy volunteers. The study protocol was approved by the Ethical committee of University Hospital Centre Osijek and Faculty of Medicine, University J.J. Strossmayer of Osijek, Croatia.

Complete blood count with differential cell analysis was performed on automated hematology analyzer (Sysmex XN 2000, Sysmex, Kobe, Japan) to confirm absence of leukocytosis/leukopenia and disturbances in relative percentages of leukocyte subpopulations. These conditions had to be fulfilled to exclude activation of peripheral blood cells by exterior antigens (pathogens). Cells were isolated by density gradient centrifugation method using Biocoll reagent (Sigma Aldrich, Darmstadt, Germany). First, whole blood was diluted with phosphate buffered saline (PBS) to a ratio of 1:1 and slowly layered over the Biocoll separating solution and centrifuged for $30 \mathrm{~min}$ at $900 \times \mathrm{g}$. Thin layer of enriched lymphocytes formed between plasma and Biocoll reagent layers was removed with Pasteur's pipette and washed twice in culture medium (Roswell Park Memorial Institute (RPMI) 1640 with addition of $10 \%$ (v/v) fetal bovine serum (FBS)) by centrifugation for $5 \mathrm{~min}$ at $400 \times g$ and room temperature (RT). After discarding the supernatant, cells were resuspended in culture medium and counted again for adjustment of AgNPs treatment.

\section{Treatment of hPBMCs}

The hPBMCs cells were treated with AgNPs, ionic Ag (in the form of $\mathrm{AgNO}_{3}$ ) and coating agents (PVP, PLL, AOT) solutions. Stock solutions of AgNPs, coating agents and $\mathrm{AgNO}_{3}$ were prepared in the UPW. Concentration of isolated hPBMCs was adjusted to the $10^{6}$ cells $/ \mathrm{mL}$. Concentration of AgNPs and exposure time for hPBMCs treatments were selected according to the cytotoxicity results reported in our previous study (20). Only concentrations that did not induce cell death and apoptosis in hPBMCs were selected for this study: 1, 2, and $3 \mathrm{mg} \mathrm{Ag} / \mathrm{L}$ for AOT-, PVP- and PLL-coated AgNPs, $0.5,1$ and $1.5 \mathrm{mg} \mathrm{Ag} / \mathrm{L}$ for BSA-AgNPs, 0.5 and $1 \mathrm{mg} \mathrm{Ag} / \mathrm{L}$ for $\mathrm{AgNO}_{3}, 0.00025 \%$ (v/v) PVP, $0.00003 \%$ (v/v) PLL and $0.0003 \%(\mathrm{v} / \mathrm{v})$ AOT. Incubation time for early activation was $6 \mathrm{~h}$ and $24 \mathrm{~h}$ for intermediate activation. Samples were incubated in the dark at $37{ }^{\circ} \mathrm{C}$ and $5 \% \mathrm{CO}_{2}$ atmosphere. After treatments, cells were washed with PBS by centrifugation for $5 \mathrm{~min}$ at $400 \times g$ and RT.

For positive control, lymphocyte subset of hPBMCs were stimulated with combination of $25 \mu \mathrm{g} / \mathrm{L}$ of phorbol myristate acetate (PMA) and $1 \mu \mathrm{M}$ of ionomicin. For negative control, lymphocytes and monocytes were cultivated in AgNPs-free exposure media. Positive control was used to confirm the ability of lymphocytes to get activated by the stimuli. Negative control was used to ensure that cells were not previously activated by outside stimuli or by isolating process. Also, negative control was used to set up the separation quadrants during the FCM analysis. The same incubation conditions were applied for the control cells as for the treated cells.

\section{Staining protocols for FCM analysis}

After treatment, cells were washed, and cell count was adjusted again with PBS to $1 \times 10^{5}$ cells $/ \mathrm{mL}$ per tube. The hPBMCs were stained to screen for monocytes, T-, B- and NK-cell, as well as to evaluate their activation in one-tube antibody panels (Table 1). Prior to staining with antibodies for FCM analysis, cells were stained for 
Table 1 Antibody panels and reagents used for hPBMCs screening and activation assessment after treatment with AgNPs

\begin{tabular}{llc}
\hline Subsets of hPBMCs & $\begin{array}{l}\text { One-tube antibody panels for screening and activation } \\
\text { analysis }\end{array}$ & Reagents $^{\text {a }}$ \\
\hline B- and NK-cells & Viobility 405/520/CD3 FITC/CD16+56 PE/CD45 & MACS Viobility 405/520; BD Multitest CD3/ \\
& PerCP/CD19 APC/CD69 VioBlue & CD16+56/CD45/CD19; MACS anti-CD69 VioBlue \\
T-cells (helper and cytotoxic) & Viobility 405/520/CD3 FITC/CD8 PE/CD45 PerCP/ & MACS Viobility 405/520; BD Multitest CD3/CD8/ \\
& CD4 APC/CD69 VioBlue & CD45/CD4; MACS anti-CD69 VioBlue \\
Monocytes & CD14 FITC/CD25 PE/HLA-DR PerCP & BD anti-CD14 FITC; BD anti-CD25 PE; BD anti-HLA- \\
& & DR PerCP
\end{tabular}

${ }^{\mathrm{a}} B D$ Becton Dickinson (Franklin Lakes, NJ, USA), MACS magnetic cell separation (Miltenyl Biotec, Bergisch Gladbach, Germany), FITC fluorescein isothiocyanate, $P E$ phycoerythrin, $\operatorname{Per} C P$ peridinin-chlorophill-protein

viability using $1 \mu \mathrm{L}$ Viobility 405/520 fixable dye (Miltenyl Biotec, Bergisch Gladbach, Germany) for $100 \mu \mathrm{L}$ of hPBMCs. After 15 min incubation at RT in the dark, cells were washed with blocking buffer (PBS $+1 \%$ FCS), $2 \mu \mathrm{L}$ of FcR block was added and cells were incubated for $10 \mathrm{~min}$ at $4{ }^{\circ} \mathrm{C}$. Then, $70 \mu \mathrm{L}$ of solution containing monoclonal antibodies (Table 1) for immunofluorescent staining were added to $100 \mu \mathrm{L}$ of hPBMCs. Cells were incubated for $30 \mathrm{~min}$ at RT in the dark and washed with $4 \mathrm{~mL}$ of staining buffer (PBS $+1 \% \mathrm{FCS}, 0.1 \% \mathrm{NaN}_{3}$ ) using centrifugation at $400 \times g$ for $5 \mathrm{~min}$ at RT. After discarding supernatant, cells were resuspended in $400 \mu \mathrm{L}$ fixation buffer (PBS $+4 \%$ formaldehyde) and vortexed prior to the cytometer acquisition.

Screening panel for T-cells encompassed antibodies for surface marker of T-cells (pan T-cell marker CD3) and T-cell subpopulation of T-helper (CD3 and CD4) and T-cytotoxic (CD3 and CD8) cells. Screening panel for Band NK-cells encompassed antibodies for surface markers of B-cells (pan B-cell marker CD19) and NK-cells (CD3 and CD16/CD56). For analysis of early (6 h) and intermediate $(24 \mathrm{~h})$ activation of lymphocytes, expression of CD69 early activation marker was assessed simultaneously with markers for cell screening to efficiently discriminate activated and non-activated cells. Screening panel for monocytes encompassed antibodies for surface marker of mature monocytes (CD14 and HLA-DR), while CD25 activation marker was assessed to analyze monocyte intermediate activation ( $24 \mathrm{~h})$. The activation markers CD25 and HLA-DR was assessed only for analysis of monocytes subpopulation as preliminary experiment did not show change in their expression on $\mathrm{T}$ - and B-cell surface even after $24 \mathrm{~h}$ of incubation with AgNPs.

The acquisition of cells was performed on flow cytometer BD LSR II equipped with software BD FACSDiva 8.0.1 (Becton Dickinson, Franklin Lakes, NJ, USA). Data for $\%$ of hPBMCs subsets and mean fluorescent intensity (MFI) for T-helper and T-cytotoxic cells were obtained by the FlowJo 10.7.1 software (TreeStar Inc/FlowJo LLC, Ashland, Oregon, USA).

\section{Statistical analysis}

Statistical analysis was conducted using program Statistica (version 12.0, Statsoft Inc., Tulsa, SAD). The distribution normality was tested by Shapiro-Wilk $W$ test. Parametric tests were used when normal data distribution was assumed. Otherwise, non-parametric tests were used.

In the analysis of the results of immunomodulatory effects, the differences of several independent groups were tested. Those groups included the untreated (control) group and experimental groups treated with four types of AgNPs at three concentration and two time points. Results were not normally distributed, so the differences between groups were tested by Kruskal-Wallis test with post hoc Dunn test.

In the analysis of surface expressions of CD4 and CD8 receptors on T-helper and T-cytotoxic cells, respectively, numerical variables were normally distributed, so the differences between two independent groups (control and experimental, i.e., untreated and treated) for all types of AgNPs were tested using the Student's $t$-test.

In control experiments including immunomodulatory effects of coatings themselves and ionic Ag, differences between two independent groups (untreated and treated) were tested. In this case, results did not follow the normal distribution, so the differences between groups were tested by Mann Whitney $U$-test.

\section{Results}

\section{Physicochemical characteristics of AgNPs}

Evaluation by the DLS, ELS and TEM revealed that freshly prepared AgNPs were of desired properties and colloidal stability. All AgNPs were spherical with primary size close to $10 \mathrm{~nm}$ and monomodal volume-weighted size distribution in water (Fig. 1). The ELS data confirmed positive and negative $\zeta$ potential for PLL-AgNPs and AOT-AgNPs due to the functionalization with positively charged PLL and negatively charged AOT, respectively. Negative $\zeta$ potential 

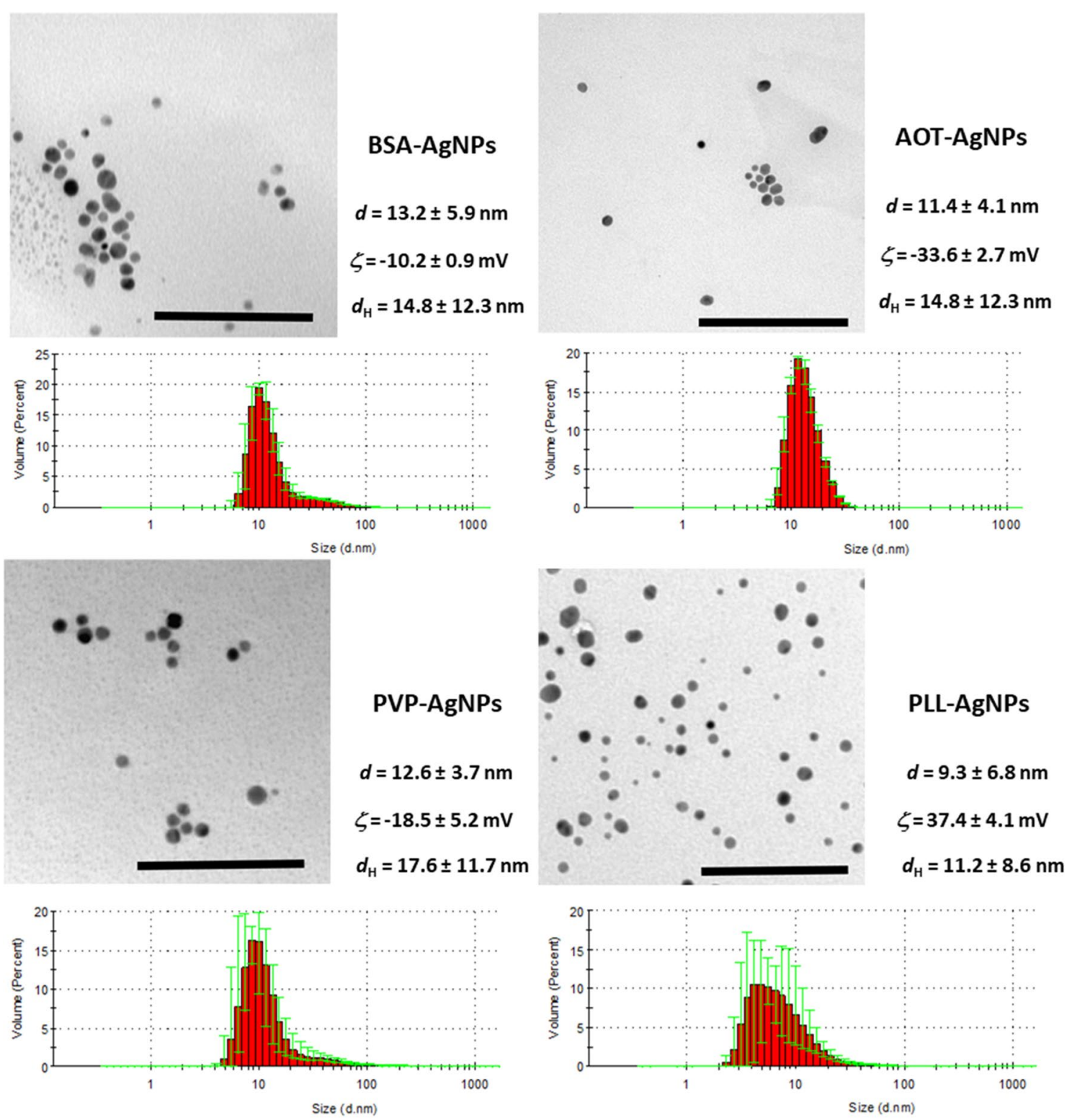

Fig. 1 Transmission electron micrographs show shape and primary sizes $(d, \mathrm{~nm})$ of different AgNPs coated with AOT, PVP, PLL and BSA dispersed in ultrapure water (scale bars present $100 \mathrm{~nm}$ ). Hydro-

dynamic diameters $\left(d_{\mathrm{H}}, \mathrm{nm}\right)$ were obtained from size distributions by volume using DLS method and $\zeta$ potential values $(\mathrm{mV})$ were measured by the ELS method

of PVP-AgNPs was a result of the attachment of $\mathrm{BH}_{4}^{-}$anions to the nanosurface during synthesis, while overall negative charge of BSA contributed to negative $\zeta$ potential of BSA-AgNPs (Fig. 1). None of the prepared AgNPs released more than $0.4 \%(\mathrm{v} / \mathrm{v})$ ionic $\mathrm{Ag}$ as revealed by the dissolution experiments explained and reported in our previous studies $[7,17,19,20]$.

\section{Effect of AgNPs on lymphocytes}

Lymphocytes were analyzed after exposure to different concentrations of AgNPs for $6 \mathrm{~h}$ and $24 \mathrm{~h}$. Negative control

were untreated, stained lymphocytes marked as QC(-), while positive controls were stained cells stimulated with PMA/ ionomicin and marked as $\mathrm{QC}(+)$. Lymphocyte subpopulations were gated according to expression of their specific pan markers (Fig.s S1-S4 in Supporting Information).

Results showed no significant AgNPs effect on \% of T-cells, cytotoxic and helper subpopulations of T-cells (Fig. 2), as well as on the relative count of B-cells and NKcells (Fig. 3).

Treatment with AgNPs did not result in the activation of T-cells (Fig. 4), but the highest concentration ( $3 \mathrm{mg} \mathrm{Ag} / \mathrm{L}$ ) of PLL-AgNPs and BSA-AgNPs significantly decreased CD4 


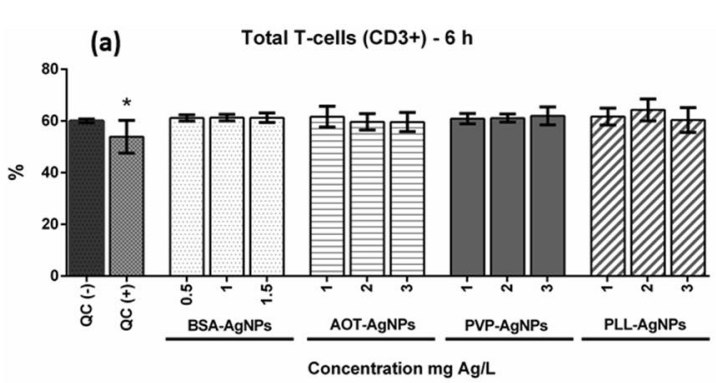

(c)

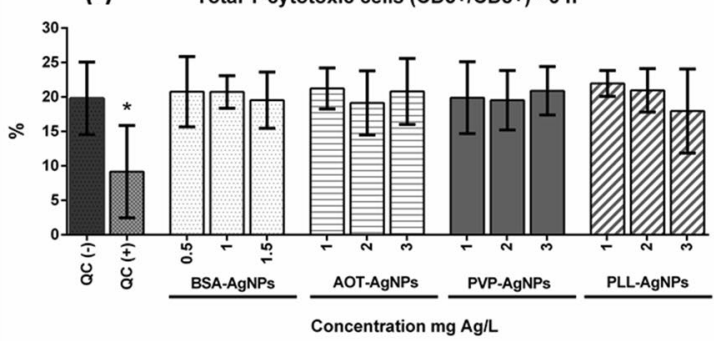

(e) Total T-helper cells $(C D 3+C D 4+)=6 \mathrm{~h}$

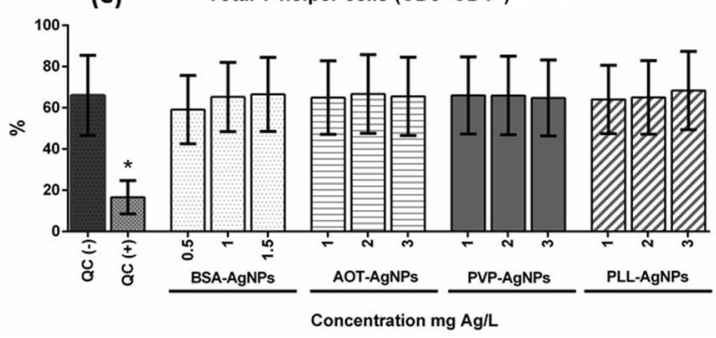

Fig. 2 Changes in percentages of total T-cells, T-cytotoxic and T-helper cells after exposure to different AgNPs for $6 \mathrm{~h}$ (a, c and e graphs, respectively) and $24 \mathrm{~h}$ (b, d and f graphs, respectively). Results obtained by the FCM analysis are presented as percentages (\%) of treated cells positive for specific surface markers, compared

antigen density on T-helper cells and CD8 antigen density on T-cytotoxic cells after 6-h exposure (Fig. 5a, c). However, this was not observed after $24 \mathrm{~h}$ exposure to AgNPs (Fig. 5b, d).

Activation of B-cells after treatment with AgNPs followed dose-dependent response for all AgNPs types, except for the AOT-AgNPs. However, significant change in B-cell activation was observed only for the highest concentration of BSA- and PLL-coated AgNPs at both 6-h and 24-h exposure (Fig. 6a, b). Similar results were obtained for the NKcells. After 6-h exposure to AgNPs, significant activation was observed for the treatment with the highest concentration of BSA-AgNPs (Fig. 6c), while the 24-h treatment with the highest concentration of both the PLL- and BSA-coated AgNPs activated NK-cells (Fig. 6d).

\section{Effect of AgNPs on monocytes}

Monocyte cell population was analyzed after exposure to different concentrations of AgNPs for $24 \mathrm{~h}$. Control

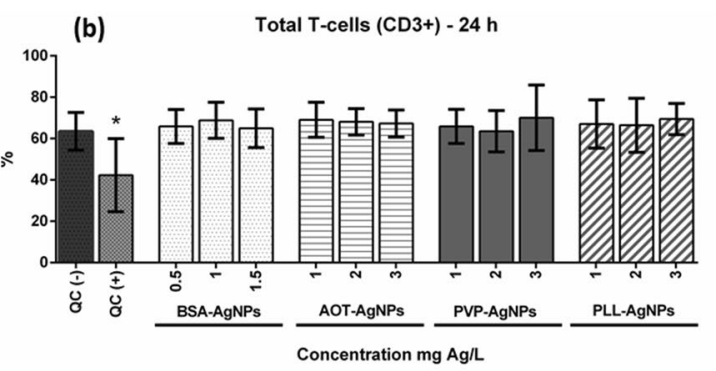

(d) Total T-cytotoxic cells $(\mathrm{CD} 3+\mathrm{CD} 8+)-24 \mathrm{~h}$
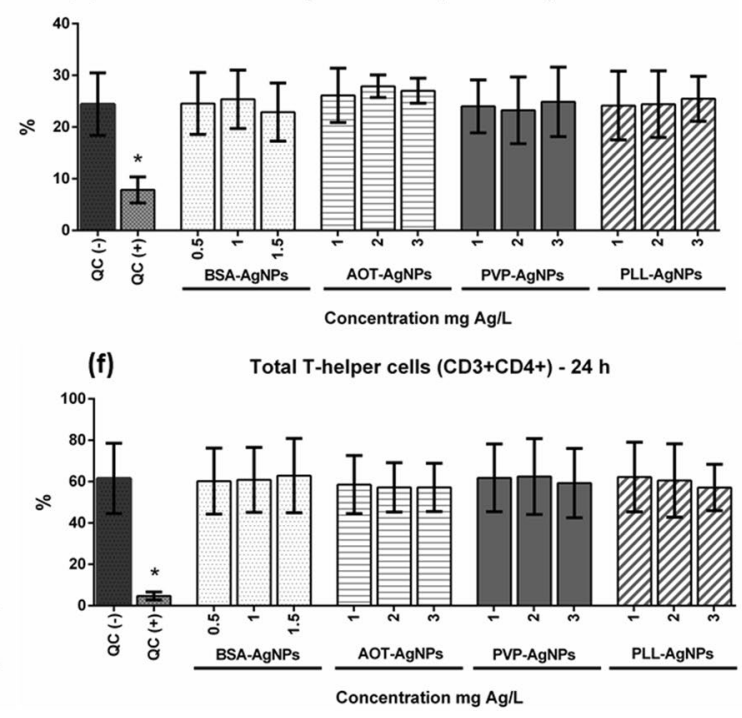

to negative controls (QC( - ), untreated, stained lymphocytes). Positive controls were stained cells stimulated with PMA/ionomicin and marked as $\mathrm{QC}(+)$. The data present the mean of three independent experiments, including SD as error bars

(untreated, stained) monocytes are marked as QC(-). To ensure that only true monocytes were analyzed, a special strategy was employed to gate only CD14/HLA-DR expressing cells (see Fig. S5 in the Supporting Information). Activation of monocytes were evaluated by the analysis of changes in the expression of CD25 marker in the population of true monocytes. Results showed that exposure to different AgNPs for $24 \mathrm{~h}$ did not significantly affect neither percentages of total (Fig. 7a) nor the percentages of activated monocytes (Fig. 7b).

\section{Effect of coating agents and ionic silver on hPBMCs}

To reveal the role of ionic $\mathrm{Ag}$ and coating agents that may be potentially released from the surface of AgNPs, the same analysis was performed for the $\mathrm{AgNO}_{3}$, PVP, PLL and AOT. Concentrations of 0.5 and $1 \mathrm{mg} \mathrm{Ag} / \mathrm{L}$ were selected for the treatment as $\mathrm{AgNO}_{3}$ did not affect viability of hPBMCs at these levels [17]. In the case of PLL, AOT and PVP, concentrations were selected according to the calculated total 
(a)

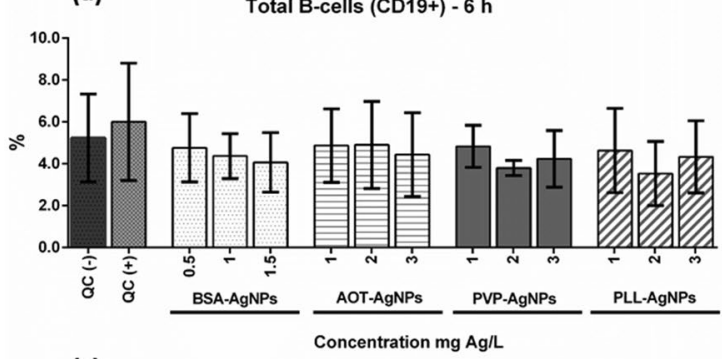

(c)

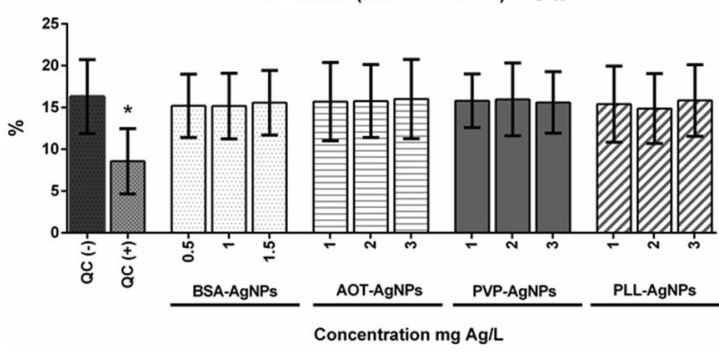

Fig. 3 Changes in percentages of total B-cells and NK-cells after exposure to different AgNPs for $6 \mathrm{~h}$ (a and $\mathbf{c}$ graphs, respectively) and $24 \mathrm{~h}$ (b and $\mathbf{d}$ graphs, respectively). Results obtained by the FCM analysis are presented as percentages (\%) of treated cells that express specific surface markers, compared to negative controls (QC(-) -

amount of these agents that are present in the suspensions of $3 \mathrm{mg} \mathrm{Ag} / \mathrm{L}$ of AgNPs (0.00003, 0.0003 and $0.00025 \%$, respectively), as this was the highest concentration that was selected for the treatment of hPBMCs with AgNPs. The soluble BSA was not included, as its amount in the suspension of BSA-AgNPs is negligible compared to the total amount of albumin in human blood.

The treatment with ionic Ag, AOT, PLL and PVP did not change the percentages of total hPBMCs subpopulations, but analysis of their activation revealed interesting results. Total subpopulation of T-cells was activated by the $1 \mathrm{mg} \mathrm{Ag} / \mathrm{L}$ of $\mathrm{AgNO}_{3}$ after both exposure times (Fig. 8a, b). However, no significant activation with $\mathrm{AgNO}_{3}$ was observed when subpopulations of T-cytotoxic and T-helper cells were analyzed (Fig. 8a, b). Coating agents at the applied doses did not affect T-cells.

Similar results of the $\mathrm{Ag}^{+}$effects were obtained for the activation of B-and NK-cells (Fig. 9). In the case of B-cells, activation occurred after $24 \mathrm{~h}$ by the treatment with $1 \mathrm{mg}$ $\mathrm{Ag} / \mathrm{L}$ of $\mathrm{AgNO}_{3}$, while NK-cells were more sensitive and activated already after $6 \mathrm{~h}$ of exposure (Fig. 9c), as well as already with the lower $\mathrm{Ag}^{+}$dose (Fig. 9d). Treatment with coating agents resulted in significant activation of only NKcells by the PLL, like stimulation with PMA/ionomicin.

Results obtained after treatment of monocytes for $24 \mathrm{~h}$ showed that PLL not only decreased their relative count (Fig. 10a), but also induced their activation presented as CD14 antigen downregulation (Fig. 10b). Activation of
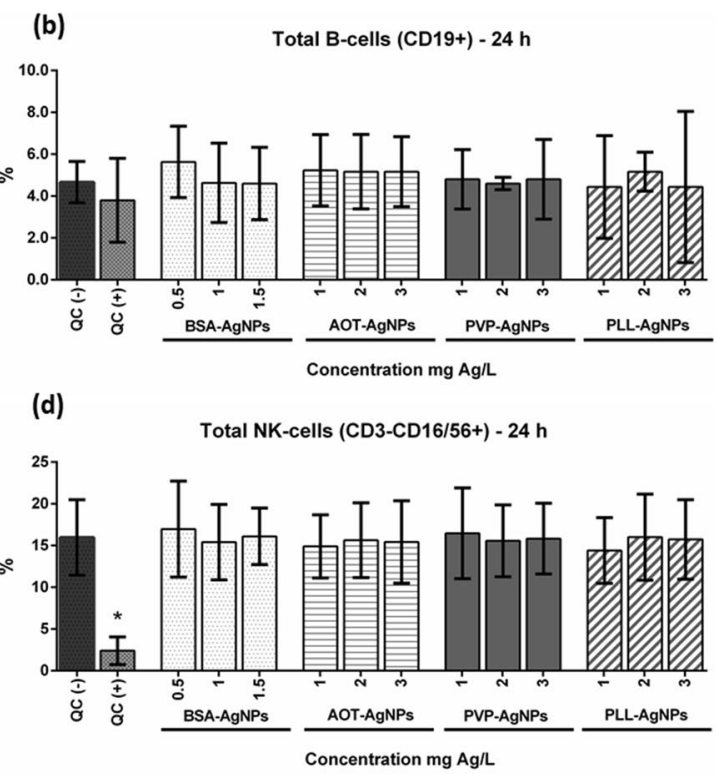

untreated, stained lymphocytes). Positive controls were stained cells stimulated with PMA/ionomicin and marked as $\mathrm{QC}(+)$. The data present the mean of three independent experiments, including SD as error bars

monocytes was observed also for the treatment with PVP, while other agents did not affect this hPBMC subpopulation.

\section{Discussion}

Although every interaction between AgNPs and immune system may result in immunotoxic or immunomodulatory outcomes, there is significant lack in scientific knowledge on how different AgNPs affect circulating immune cells. Modulation of immune response may be stimulating or suppressive, while undesirable overstimulation or oversuppression of immune system must be avoided in medical products by safe design of AgNPs-enabled materials [1,5].

Circulating immune cells in bloodstream present both innate and adaptive immune system that may interact with AgNPs. As effects on cells depend on physicochemical properties and colloidal stability of AgNPs in biological media, these should be precisely evaluated to ensure nanosafety regardless of its final intended biomedical purpose $[1,5,6]$.

This study provides data on immunomodulatory effects of differently functionalized small-sized AgNPs at non-toxic concentrations. Experimental design, including AgNPs concentration used for treatment of hPBMCs and exposure time, is based on results reported in our previous study [17]. While our previous study was focused on immunotoxic and lethal effects of AgNPs, this study aimed to evaluate AgNPs immunomodulatory effects. Immunotoxicity and 

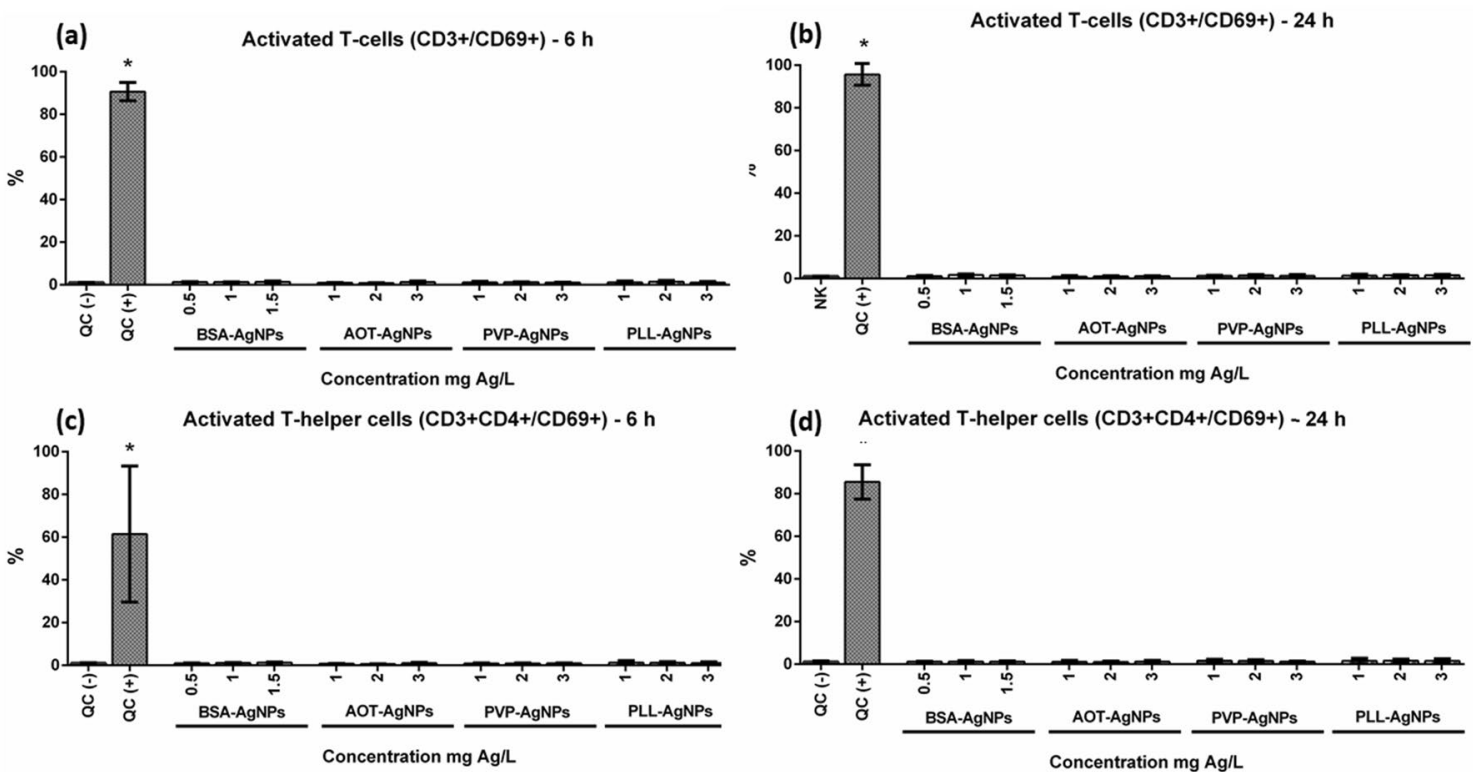

(d) Activated T-helper cells (CD3+CD4+/CD69+) $-24 \mathrm{~h}$

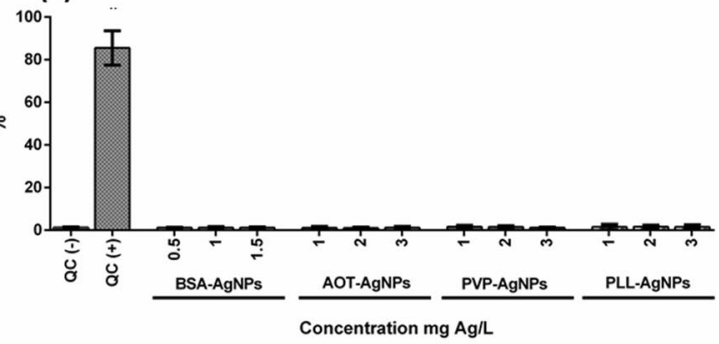

(e) Activated T-cytotoxic cells (CD3+CD8+/CD69+) - $6 \mathrm{~h}$

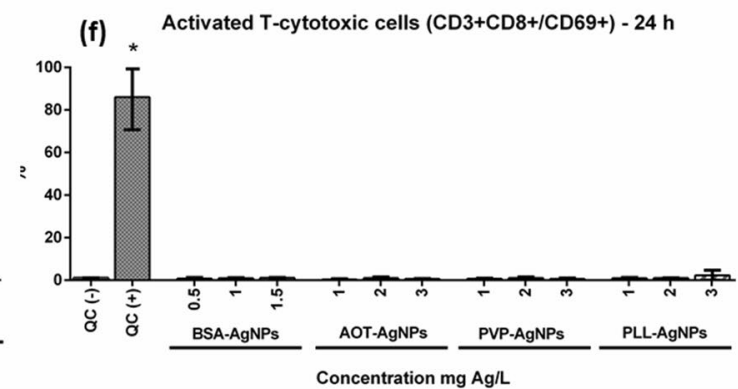

Fig. 4 Immunomodulatory effect of different AgNPs on all T-cells, T-helper and T-cytotoxic cells after exposure to different AgNPs for $6 \mathrm{~h}$ (a, c and e graphs, respectively) and $24 \mathrm{~h}$ (b, $\mathbf{d}$ and $\mathrm{f}$ graphs, respectively). Results obtained by the FCM are presented as percentages $(\%)$ of cells that express activation surface marker CD69,

immunomodulatory activity of nanomaterials should be clearly differentiated and immunotoxicity cannot be misinterpreted as immunomodulatory effects. For example, antiinflammatory and antiproliferative effects of AgNPs were investigated in many studies by evaluation of cytokine expression using immunoassays of low sensitivity and specificity $[1,21]$. Such results may be easily misinterpreted as an antiinflammatory effect, while decrease in cytokine expression may be actually caused by cytotoxic action of AgNPs, especially at higher concentrations $[1,21]$. This was also highlighted in recent study by Alsaleh et al. who investigated AgNPs oxidative stress induction prior to determination of phagocytic ability of polymorphonuclear cells (PMNCs) [22]. After exposure to citrate-coated AgNPs for $24 \mathrm{~h}$, applied concentrations that did not induce significant cell damages were used to assess phagocytic ability [22].

Here, the immunomodulatory effect of AgNPs on PBMCs was measured by changes in total and activated peripheral immune cell relative numbers. The functionality of hPBMCs

compared to negative controls (QC( - ) - untreated, stained lymphocytes). Positive controls were stained cells stimulated with PMA/ ionomicin and marked as $\mathrm{QC}(+)$. The data present the mean of three independent experiments, including SD as error bars

was assessed through surface activation antigen expression by employing similar approach reported elsewhere [18]. Although the proliferation test is the method of choice for assessing lymphocyte functionality, it is much more laborand time-consuming compared to the methodology reported in this study. The expression analysis of early (CD69) and intermediate (CD25) activation antigens may accurately determine the functionality of hPBMCs [18]. In our in vitro approach, hPBMCs were isolated from fresh human blood and exposed to PVP-, PLL-, AOT- and BSA-coated AgNPs, as well as to coating agents and $\mathrm{Ag}^{+}$ions that may be released from the AgNPs surface.

Analysis of T-cells showed that none of the tested materials at low concentrations affected adaptive cellular immunity, presented by T-cells and T-cell subsets. There was no significant activation in total T-cell population, as well as in T-helper cell and T-cytotoxic cell, which did not change the total counts after exposure to AgNPs up to the concentration of $3 \mathrm{mg} \mathrm{Ag} / \mathrm{L}$. Higher concentrations and longer exposure 


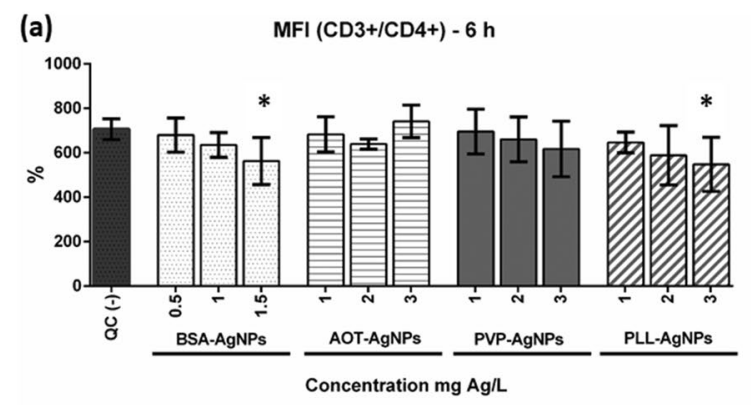

(c)

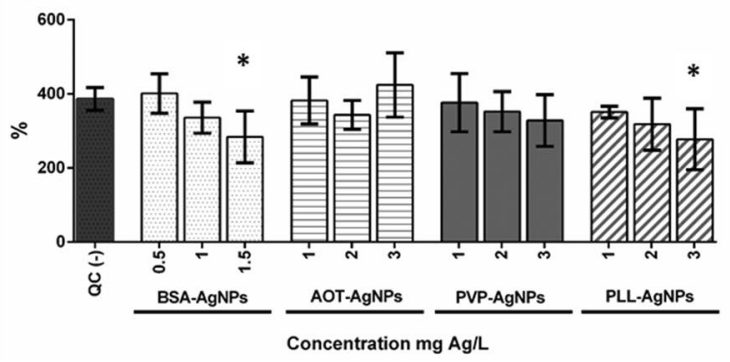

Fig. 5 Changes in the density of cell surface markers CD4 on T-helper cells and CD8 on T-cytotoxic cells, after exposure to different AgNPs for $6 \mathrm{~h}$ (a and c, respectively) and $24 \mathrm{~h}$ (b and d graphs, respectively). Results obtained by the FCM analysis are presented as

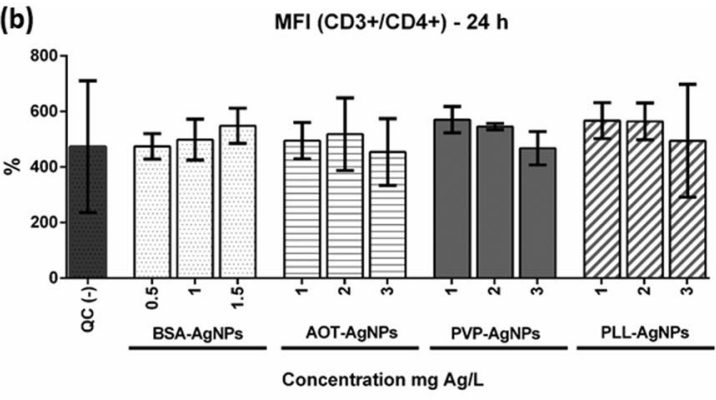

(d)

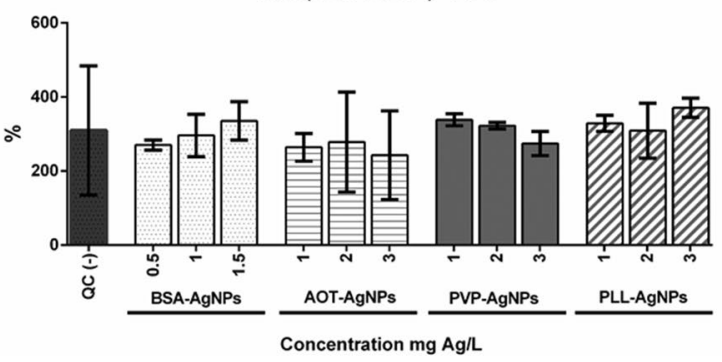

the mean fluorescence intensity (MFI) of treated cells, compared to negative control (QC( - ) - untreated, stained lymphocytes). The data present the mean of three independent experiments, including SD as error bars

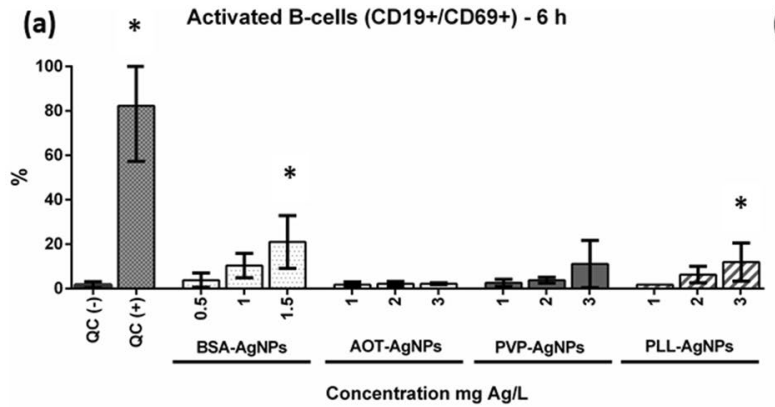

(c)

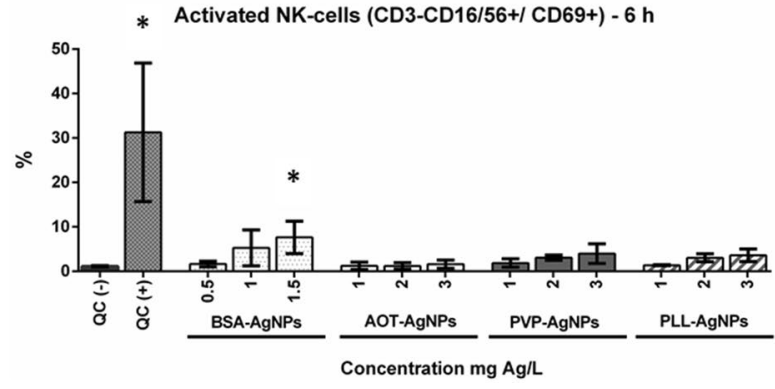

Fig. 6 Immunomodulatory effect of different AgNPs on B-cells and NK-cells after exposure to different AgNPs for $6 \mathrm{~h}$ (a and c graphs, respectively) and for $24 \mathrm{~h}$ (b and $\mathbf{d}$ graphs, respectively). Results obtained by the FCM are presented as percentages (\%) of cells that express activation surface marker CD69, compared to negative con-

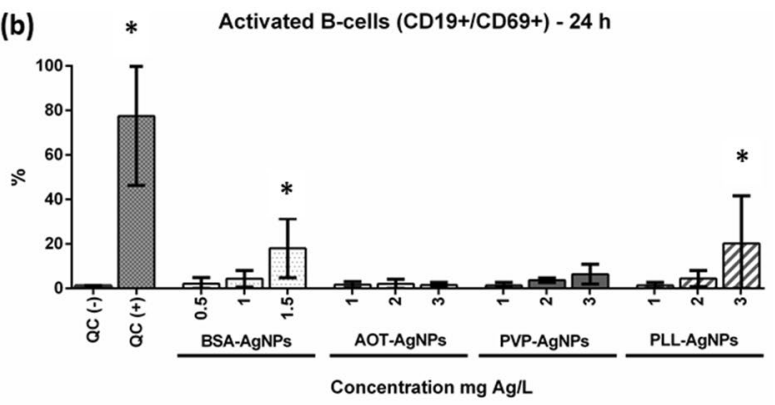

(d)

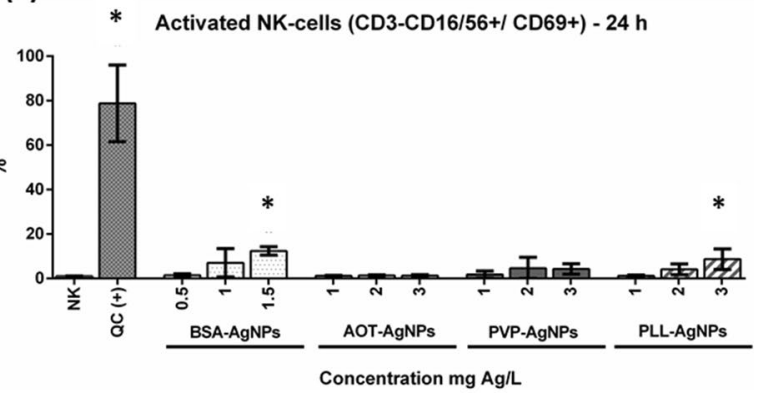

trols (QC( - ) - untreated, stained lymphocytes). Positive controls were stained cells stimulated with PMA/ionomicin and marked as $\mathrm{QC}(+)$. The data present the mean of three independent experiments, including SD as error bars 
(a)

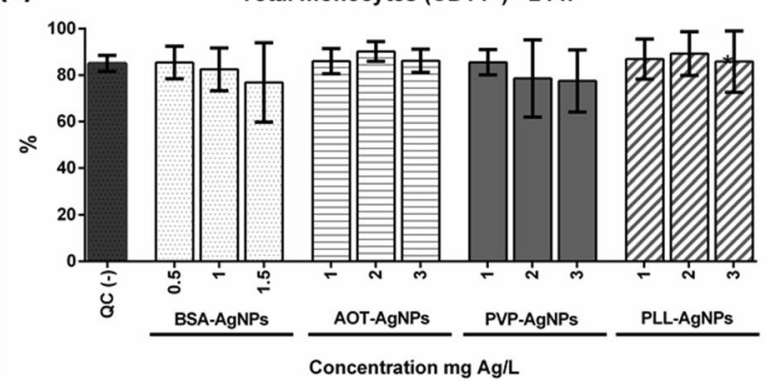

(b)

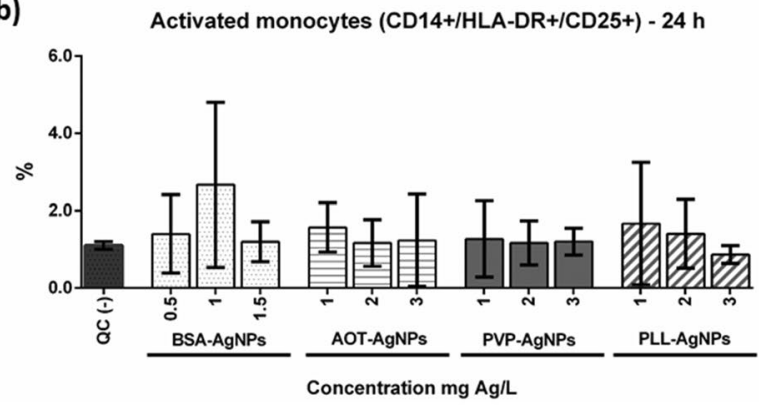

Fig. 7 Analysis of AgNPs effect on a relative count of total monocytes (CD14+/HLA-DR +) and b activated monocytes after $24 \mathrm{~h}$ of exposure Results obtained by the FCM are presented as percentages (\%) of cells that express monocyte surface markers CD14 and HLA-

time (e.g., $>24 \mathrm{~h}$ for late activation assessment) were not tested due to high cell mortality rate under such conditions. Similar in vivo experiment with small and medium-sized AgNPs revealed dose-dependent immunomodulation of T-lymphocytes and monocytes in mice, but at high concentrations [23]. Furthermore, analysis of T-cell subsets showed decreased density of surface receptors (CD4 on T-helper and CD8 on T-cytotoxic cells) after exposure to PLL- and BSAcoated AgNPs for $6 \mathrm{~h}$, but not after $24 \mathrm{~h}$. These findings are especially important for the development of anti-HIV vaccination strategy. There are many reports on the application of Ag nanomaterials for anti-HIV vaccines based on their adjuvant properties [24]. Depending on the physicochemical properties, AgNPs may act as adjuvant intracellularly, but this may increase their toxic effects in the host cells. If designed to decrease their internalization by cells, it is safer for the host cell, but there is possibility of low immune response [1]. Our results suggest the third option - AgNPs may prevent the binding of the virus to the receptor CD4 of T-helper cell. Both CD4 and CD8 are coreceptors of T-cell receptor on T-helper and T-cytotoxic cell surface, respectively. They mediate the interaction between T-cells and antigen-presenting cells, which plays the important role in antiviral defense. The CD4 molecule have the most important role in HIV-1 infection, while the role of CD8 molecule is more significant in other viral infections (e.g., HSV) [8]. HIV-1 binds to the CD4 receptor by glycoprotein 120 on its surface and enters the T-helper cells. Consequently, T-helper cell $(\mathrm{CD} 4+)$ count decreases leading to immunodeficiency [9]. Our results showed that PLL- and BSA-AgNPs decreased the number of CD4 receptors without decreasing the total count of T-helper cell. Therefore, these AgNPs types may block the viral activity by blocking the binding of the virus to T-helper cells. These results signify a great potential of AgNPs in antiviral therapeutic strategy.

Analysis of NK-cell subpopulation revealed that BSAAgNPs significantly activated NK-cells not changing their
$\mathrm{DR}$, as well as activation surface marker CD25, compared to negative controls (QC( - ) —untreated, stained lymphocytes). The data present the mean of three independent experiments, including SD as error bars

total count, whereas PVP- and PLL-AgNPs also induced their activation although results were not statistically significant. The NK-cells provide innate immune defence against viral infections by direct targeting and killing infected cells or indirectly by modulation of adaptive T-cell response [25]. The degree of NK-cells activation determines if health outcomes of infection would be under or out of control [25]. Immunomodulation ability of NK-cells may be useful in antitumor strategy as it is believed that the enhancement of NK-cell levels can limit the spread of tumor or decrease its size as showed in the case of magnetic $\left(\mathrm{Fe}_{3} \mathrm{O}_{4} / \mathrm{SiO}_{2}\right) \mathrm{NPs}$ [3].

Scientific evidences for the effect of NPs on B-cells are rare and contradictory. Until now, it was believed that metallic NPs do not activate B-cells, unless coated with the antigens [5]. Specific antibody production towards NPs per se was only reported for the iron oxide NPs, [3, 5] while the induction of humoral immunity for vaccination purposes was only reported for protein-coated calcium phosphate NPs [26]. Results of our study showed that protein-coated BSAAgNPs and polymer-coated PLL-AgNPs significantly activated $B$-cells already after $6 \mathrm{~h}$ of exposure and the $\%$ of activated B-cells did not change after $24 \mathrm{~h}$ of exposure. These results highlight the possibility of an early and intermediate B-cell activation by specifically functionalized AgNPs that may motivate innovation in AgNPs design towards modulation of humoral immune response. Depending on potential applications, further investigations of AgNPs effect on overall adaptive (cellular and humoral) immunity are needed.

Our study also included the expression analysis of low affinity surface receptor for interleukin-2 (IL-2 R $\alpha$ or CD25), which is the marker of an intermediate cell activation. Although CD25 is typically considered as a T-cell surface marker, it is also functional on monocytes, participating in monocyte activation or in monocyte-mediated T-cell activation [27]. Thus, we analyzed the CD25 expression for both T-cells and monocytes. In the case of $\mathrm{T}$-cells, there was not any change in CD25 expression on 
(a)

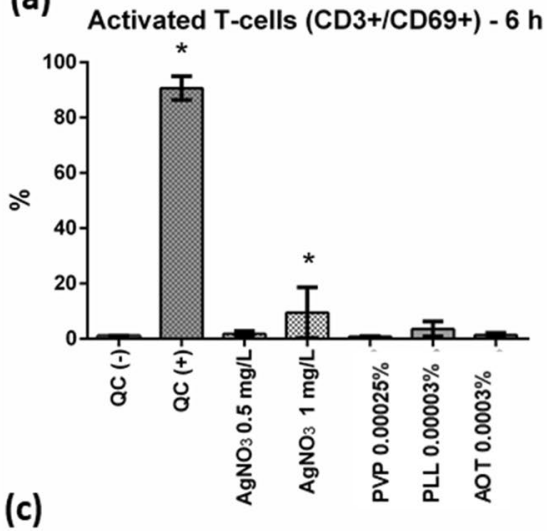

(c)

Activated T-cytotoxic cells (CD3+CD8+/CD69+) - $6 \mathrm{~h}$

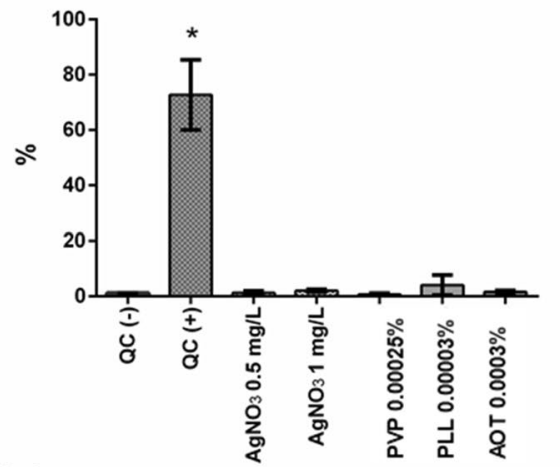

(e)

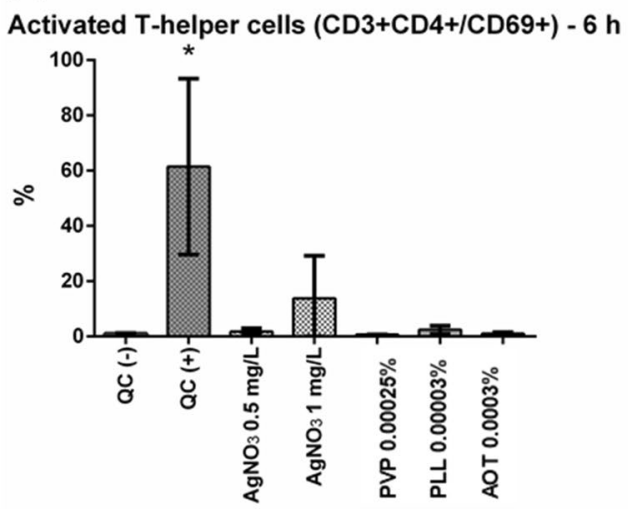

Fig. 8 Immunomodulatory effect of $\mathrm{AgNO}_{3}$, PVP, PLL and AOT on total T-cells, T-cytotoxic and T-helper cells after exposure for $6 \mathrm{~h}$ (a, c and e graphs, respectively) and $24 \mathrm{~h} \mathrm{(b,} \mathbf{d}$ and $\mathbf{f}$ graphs, respectively). Results obtained by the FCM are presented as percentages (\%) of cells that express activation surface marker CD69, compared

the cell surface, while monocytes showed some changes. We applied special gating strategy to simultaneously identify true monocytes and activated monocyte subsets by analysis of normal and decreased co-expression of CD14/ HLA-DR antigens, respectively [27]. The highest increase in CD25 expression on true monocytes was observed after $24 \mathrm{~h}$ exposure to $1 \mathrm{mg} \mathrm{Ag} / \mathrm{L}$ of BSA-AgNPs. The increase was also observed after the treatment with the lowest dose

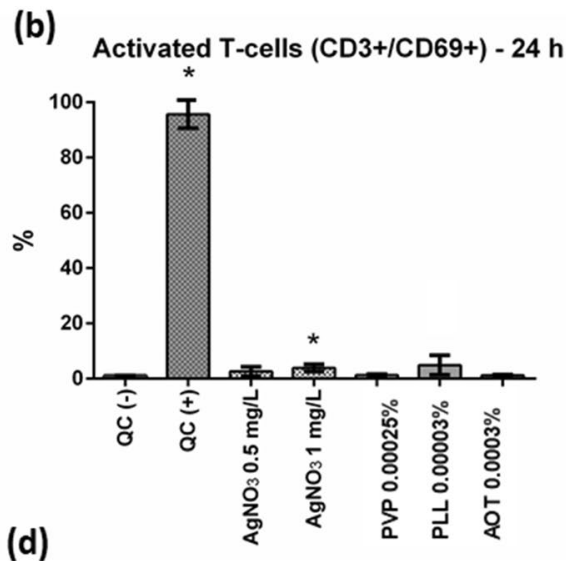

Activated T-cytotoxic cells (CD3+CD8+/CD69+) - $24 \mathrm{~h}$

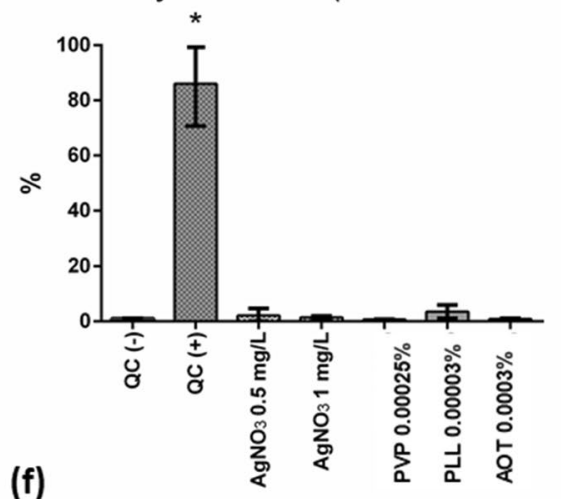

Activated T-helper cells (CD3+CD4+CD69+) - $24 \mathrm{~h}$

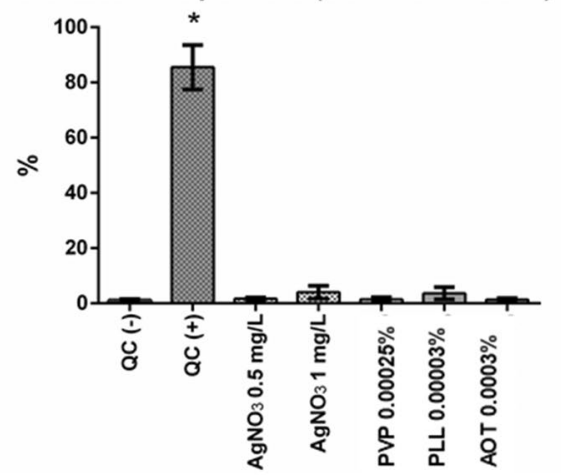

to negative controls (QC( - ) —untreated, stained lymphocytes). Positive controls were stained cells stimulated with PMA/ionomicin and marked as $\mathrm{QC}(+)$. The data present the mean of three independent experiments, including SD as error bars

of AOT- and PLL-AgNPs. However, these results were not significantly different from untreated cells. Literature data are somewhat contradictory. Côté et al. found increased CD25 expression on T-cells after exposure to AgNPs, but decreased T-cell proliferation [28]. Li et al. developed an in vitro model for assessment of nanoimmunosafety based on activation of human primary monocytes [29]. By applying this model in evaluation of AgNPs and AuNPs 
(a) Activated B-cells (CD19+/CD69+) - $6 \mathrm{~h}$

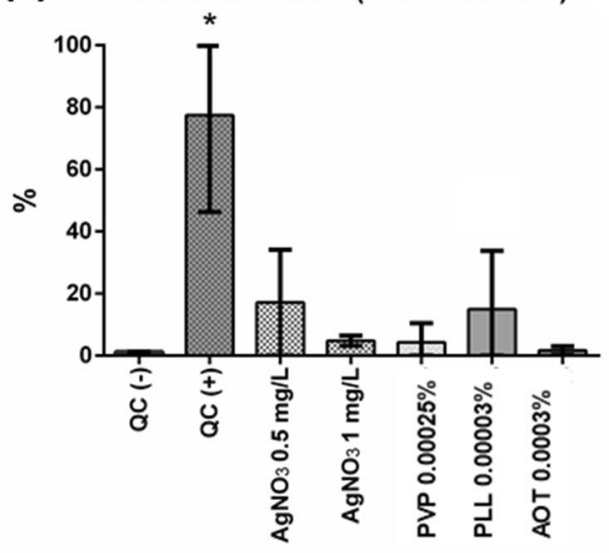

(c)

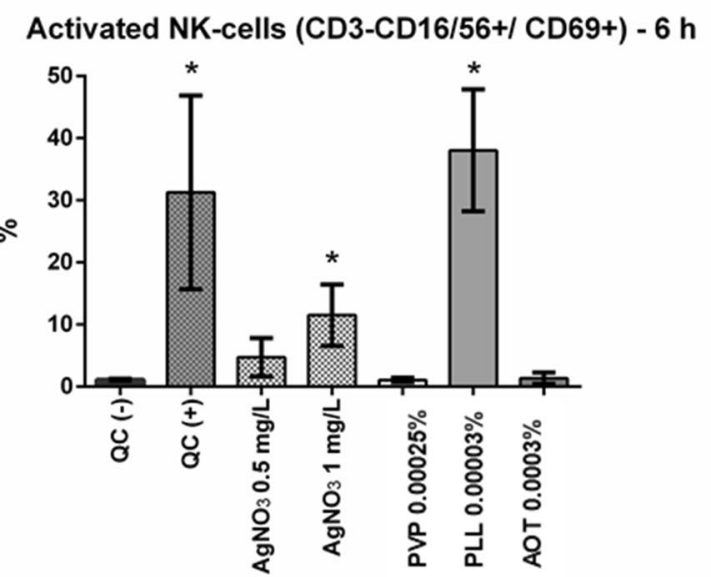

Fig. 9 Immunomodulatory effects of $\mathrm{AgNO}_{3}$, PVP, PLL and AOT on $\mathrm{B}$-cells and NK-cells after exposure for $6 \mathrm{~h}$ (a and $\mathbf{c}$ graphs, respectively) and $24 \mathrm{~h}$ (b and $\mathbf{d}$ graphs, respectively). Results are presented as percentages $(\%)$ of cells that express activation surface marker

immunotoxicity, they concluded that these NPs do not directly activate monocytes [29].

Finally, to elucidate immunomodulatory action of coating agents themselves and ionic Ag form that could be released from the AgNPs surface in complex biological environment, control experiments employed $\mathrm{Ag}^{+}$at concentration that were not toxic to hPBMCs, [17] as well as PVP, PLL and AOT at concentration that corresponded to their total amount in $3 \mathrm{mg} \mathrm{Ag} / \mathrm{L}$ of AgNPs suspension. Obtained results clearly showed ability of $\mathrm{Ag}^{+}$to activate T-cells, B-cells and NK-cells, but not monocytes. However, increased activation of these cells was observed only after exposure to $1 \mathrm{mg} \mathrm{Ag} / \mathrm{L}$ of $\mathrm{Ag}^{+}$, that is one order of magnitude higher than what can be expected as released fraction from nanosurface at AgNPs concentrations tested in this study. Therefore, observed activation of B- and NK-cells and decreased density of surface receptors on T-helper and T-cytotoxic cells after exposure to AgNPs cannot be attributed only to dissolved Ag fraction,

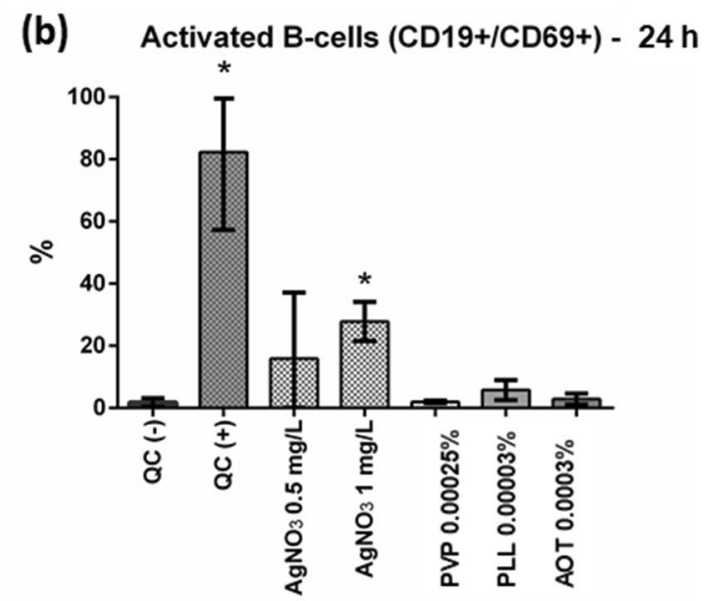

(d)

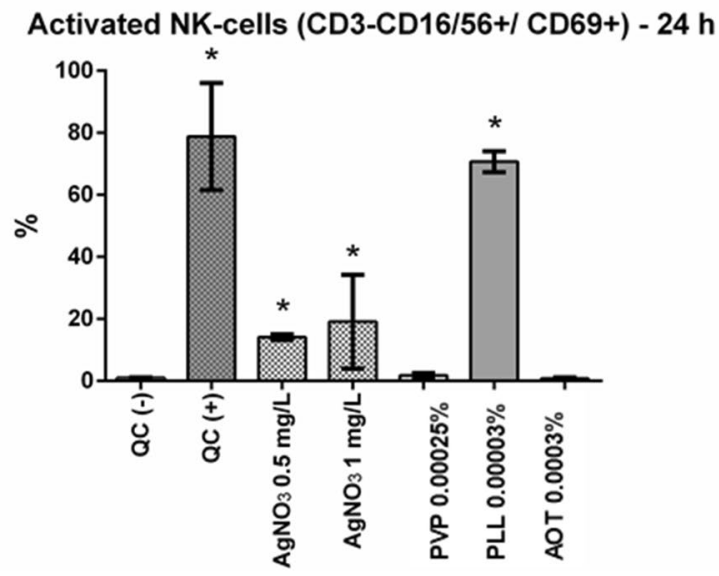

CD69, compared to negative controls (QC( - ) - untreated, stained lymphocytes). Positive controls were stained cells stimulated with PMA/ionomicin and marked as QC(+). The data present the mean of three independent experiments, including SD as error bars

but nanoparticulate form also played the important role. These findings do not fully support conclusion of Haase et al. [30] who established that health effects of AgNPs, including immunomodulation, are not specific for nanoparticulate form but for released $\mathrm{Ag}^{+}$fraction [30].

Assessment of hPBMC response to coating agents revealed that only PLL significantly activated B- and NKcells, while activation of monocytes was induced by PLL and PVP. As hPBMC activation by PLL (and by PVP in the case of monocytes) was much higher than activation of these cells by AgNPs functionalized by these agents, one may assume that coating agents were responsible for AgNPs immunomodulatory effects. Indeed, release of coating agents from the AgNPs may occur in biological environment during protein corona formation when coating agents may be replaced by proteins. As we were not able to determine such events due to technical and instrumental constraints, we leave it as possible scenario. However, immunomodulatory 
(a) Total monocytes (CD14+) - $24 \mathrm{~h}$

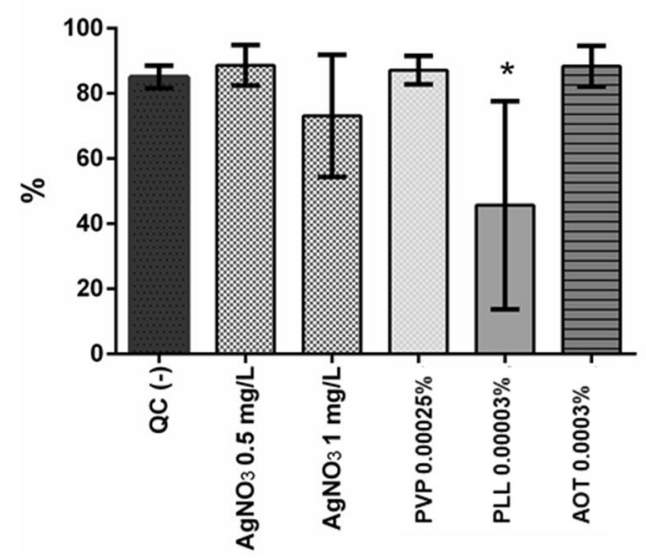

(b)

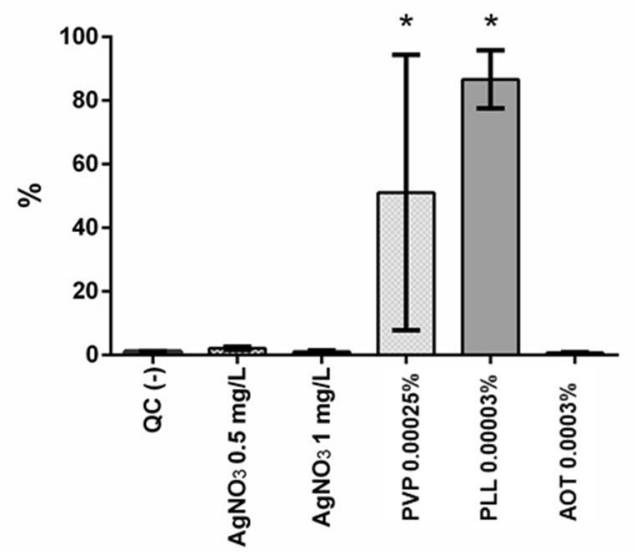

Fig. 10 Effect of $\mathrm{AgNO}_{3}$, PVP, PLL and AOT on a relative count of monocytes (CD14+/HLA-DR + ) and $\mathbf{b}$ activated monocytes $(\mathrm{CD} 14+/ \mathrm{HLA}-\mathrm{DR}+/ \mathrm{CD} 25+)$ after $24 \mathrm{~h}$ of exposure. Results obtained by the FCM are presented as percentages (\%) of cells that

effect of BSA-AgNPs cannot be explained by the same hypothesis as BSA itself is endogenous agent and present in human blood at high concentration. If immunomodulatory activity of PLL-AgNPs is imputed to the PLL action, then protein-coated BSA-AgNPs arise as the most potent for interaction with immune system.

The Scientific Committee on Emerging and Newly Identified Health Risks (SCENIHR) in their Guidance on the determination of potential health effects of nanomaterials used in medical devices suggested the parallel testing of $\mathrm{Ag}^{+}$ control during risk assessment of AgNPs [31]. Based on our results; we suggest obligatory additional control experiments by evaluating immunocompatibility of functionalization agents used for surface functionalization of nanomaterials.

\section{Conclusion}

This study provides several new ideas on the use of AgNPs for antitumor, antiviral, and other therapeutic purposes that involve interaction with immune system. The immunomodulatory potential of different AgNPs was evaluated by analysis of surface markers expression of different subpopulations of hPBMCs exposed to AgNPs for 6 or $24 \mathrm{~h}$ in low concentrations. Study included four different AgNPs of the same size, same colloidal stability and dissolution behavior that differed only in the zeta potential due to different coating agents used for surface stabilization. The results revealed that surface functionalization impact immunomodulatory abilities of AgNPs in combination with protein corona formation in biological media. Our results also showed a more pronounced influence of AgNPs on adaptive immunity, but express monocyte surface markers CD14 and HLA-DR, as well as activation surface marker CD25, compared to negative controls (QC(), untreated, stained lymphocytes). The data present the mean of three independent experiments, including SD as error bars

also a certain impact on innate immunity; the combination of these effects is very important in the development of novel antiviral and antitumor therapeutic strategies. Thus, design of novel AgNPs-enabled medical products should be accompanied by careful evaluation of their immunocompatibility considering immune system complexity by following standardized and clinically relevant protocols.

Supplementary Information The online version contains supplementary material available at https://doi.org/10.1007/s00775-021-01898-0.

Acknowledgements This research was funded by the Croatian Science Foundation (grants number HRZZ-IP-2016-06-2436 and HRZZ-IP-2016-06-1137).

\section{Declarations}

Conflict of interest There are no conflicts of interest to declare.

Ethical approval All work described in this manuscript has been carried out in accordance with The Code of Ethics of the World Medical Association (Declaration of Helsinki).

Informed consent The informed consent was obtained from healthy human subjects who provided their blood samples on a voluntary basis.

\section{References}

1. Ninan N, Goswami N, Vasilev K (2020) The impact of engineered silver nanomaterials on the immune system. Nanomaterials 10(5):967

2. Klippstein R, Fernandez-Montesinos R, Castillo PM, Zaderenko AP, Pozo Perez D (2010) Silver nanoparticles interactions with the immune system: implications for health and disease. In: Pozo 
Perez D (ed) Silver nanoparticles, IntechOpen, London, p 309 324. Available from: https://www.intechopen.com/chapters/9728.

3. Luo YH, Chang LW, Lin P (2015) Metal-based nanoparticles and the immune system: activation, inflammation, and potential applications. Biomed Res Int 2015:143720

4. AL-Rahman A, Munaf R, Ibrahim SR, AL-Aqidi I (2016) The effect of silver nanoparticles on cellular and humoral immunity of mice in vivo and in vitro. Iraqi J Biotech 15(2):21-29

5. Kononenko V, Narat M, Drobne D (2015) Nanoparticle interaction with the immune system. Arh Hig Rada Toksikol 66(2):97-108

6. Dobrovolskaia MA, Shurin M, Shvedova AA (2016) Current understanding of interactions between nanoparticles and the immune system. Toxicol Appl 299:78-89

7. Kubo AL, Capjak I, Vinković Vrček I, Bondarenko OM, Kurvet I, Vija H, Ivask A, Kasemets K, Kahru A (2018) Antimicrobial potency of differently coated 10 and $50 \mathrm{~nm}$ silver nanoparticles against clinically relevant bacteria Escherichia coli and Staphylococcus aureus. Colloids Surf B Biointerfaces 170:401-410

8. Baram-Pinto D, Shukla S, Perkas N, Gedanken A, Sarid R (2009) Inhibition of herpes simplex virus type 1 infection by silver nanoparticles capped with mercaptoethane sulfonate. Bioconjug Chem 20:1497-1502

9. Elechiguerra JL, Burt JL, Morones JR, Camacho-Bragado A, Gao X, Lara HH, Yacaman MJ (2005) Interactions of silver nanoparticles with HIV-1. J Nanobiotechnol 3:6

10. Zhao L, Seth A, Wibowo N, Zhao CX, Mitter N, Yu C, Middelberg AP (2014) Nanoparticle vaccines. Vaccine 32:327-337

11. Wei L, Lu J, Xu H, Patel A, Chen Z-S, Chen G (2015) Silver nanoparticles: synthesis, properties, and therapeutic applications. Drug Discov Today 20(5):595-601

12. Minigo G, Scholzen A, Tang CK, Hanley JC, Kalkanidis M, Pietersz GA, Apostolopoulos V, Plebanski M (2007) Poly-L-lysinecoated nanoparticles: a potent delivery system to enchance DNA vaccine efficacy. Vaccine 25(7):1316-1327

13. Chakraborty B, Pal R, Ali M, Singh LM, Shahidur Rahman D, Kumar Ghosh S, Sengupta M (2016) Immunomodulatory properties of silver nanoparticles contribute to anticancer strategy for murine fibrosarcoma. Cell Mol Immunol 13(2):191-205

14. Guo D, Zhu L, Huang Z, Zhou H, Ge Y, Ma W, Wu J, Zhang X, Zhou X, Zhang Y, Zhao Y, Gu N (2013) Anti-leukemia activity of PVP-coated silver nanoparticles via generation of reactive oxygen species and release of silver ions. Biomaterials. https://doi.org/10. 1016/j.biomaterials.2013.07.015

15. Vinhas R, Mendes R, Fernandes AR, Baptista PV (2017) Nanoparticles-emerging potential for managing leukemia and lymphoma. Front Bioeng Biotechnol 5:79

16. Houshmand M, Garello F, Circosta P, Stefania R, Aime S, Saglio G, Giachino C (2020) Nanocarriers as magic bullets in the treatment of leukemia. Nanomaterials (Basel) 10(2):276

17. Vuković B, Milić M, Dobrošević B, Milić M, Ilić K, Pavičić I, Šerić V, Vinković Vrček I (2020) Surface stabilization affects toxicity of silver nanoparticles in human peripheral blood mononuclear cells. Nanomaterials (Basel) 10(7):1390

18. Nielsen SD, Afzelius P, Ersboll AK, Nielsen JP, Hansen J-ES (1998) Expression of the activation antigen CD69 predicts functionality of in vitro expanded peripheral blood mononuclear cells (PBMC) from healthy donors and HIV-infected patients. Clin Exp Immunol 114:66-72
19. Jurašin DD, Ćurlin M, Capjak I, Crnković T, Lovrić M, Babič M, Horák D, Vinković Vrček I, Gajović S (2016) Surface coating affects behaviour of metallic nanoparticles in a biological environment. Bellstein J Nanotechnol 7(1):246-262

20. Milić M, Leitinger G, Pavičić I, Zebić Avdičević M, Dobrović S, Goessler W, Vinković Vrček I (2014) Cellular uptake and toxicity effects of silver nanoparticles in mammalian kidney cells. J Appl Toxicol 35(6):581-592

21. Shin SH, Ye MK, Kim HS, Kang HS (2007) The effects of nanosilver on the proliferation and cytokine expression by peripheral blood mononuclear cells. Int Immunopharmacol 7:1813-1818

22. Alsaleh NB, Minarchick VC, Mendoza RP, Sharma B, Podila R, Brown JM (2019) Silver nanoparticle immunomodulatory potential in absence of direct cytotoxicity in RAW 264.7 macrophages and MPRO 2.1 neutrophils. J Immunotoxicol 16(1):63-73

23. Zelikoff J, Willis D, Degheidy H, Zhang Q, Umbreit T, Goering $P$ (2013) Immune cell profiles in response to silver nanoparticles associated with medical devices. J Immunol 190(1):202.1

24. Lo YC, Eddin MA, Powell JD (2013) Selective activation of antigen-experienced $\mathrm{T}$ cells by anti-CD3 constrained on nanoparticles. J Immunol 191:5107-5114

25. Maucourant C, Filipovic I, Ponzetta A, Aleman S, Cornillet M, Hertwig L, Strunz B, Lentini A, Reinius B, Brownlie D, Cuapio A, Ask EH, Hull RM, Haroun-Izquierdo A, Schaffer M, Klingström J, Folkesson E, Buggert M, Sandberg JK, Eriksson LI, Rooyackers O, Ljunggren HG, Malmberg KJ, Michaëlsson J, Marquardt N, Hammer Q, Strålin K, Björkström NK, Karolinska COVID-19 Study Group (2020) Natural killer cell immunotypes related to COVID-19 disease severity. Sci Immunol 5(50):6832

26. Temchura VV, Kozlova D, Sokolova V, Überla K, Epple M (2014) Targeting and activation of antigen-specific B-cells by calcium phosphate nanoparticles loaded with protein antigen. Biomaterials 35(23):6098-6105

27. Appleby LJ, Nausch N, Midzi N, Mduluza T, Allen JE, Mutapi F (2013) Sources of heterogenity in human monocyte subsets. Immunol Lett 152(1):32-41

28. Côté-Maurais G, Bernier J (2014) Silver and fullerene nanoparticles' effect on interleukin-2-dependent proliferation of CD4 (+) T cells. Toxicol In Vitro 28(8):1474-1481

29. Li Y, Italiani P, Casals E, Valkenborg D, Mertens I, Baggerman G, Nelissen I, Puntes VF, Boraschi D (2016) Assessing the immunosafety of engineered nanoparticles with a novel in vitro model based on human primary monocytes. ACS Appl Mater Interfaces 8(42):28437-28447

30. Haase H, Fahmi A, Mahltig B (2014) Impact of silver nanoparticles and silver ions on innate immune cells. J Biomed Nanotechnol 10(6):1146-1156

31. Directorate-General for Health and Consumers (European Commission) (2015) Guidance on the determination ofpotential health effects of nanomaterials used in medical devices. https://doi.org/ 10.2772/41391. Available at: http://ec.europa.eu/health/scientific_ committees/emerging/opinions/index_en.htm

Publisher's Note Springer Nature remains neutral with regard to jurisdictional claims in published maps and institutional affiliations. 